Artículo

\title{
Epidemias y comercio (i)lícito en el sur de Europa: Mallorca, siglo XIX
}

\author{
Pere Salas-Vives* (DD \\ Universidad de las Islas Baleares
}

\author{
Joana Maria Pujadas-Mora (DD \\ Universitat Oberta de Catalunya \\ Centro de Estudios Demográficos (Universidad Autónoma de Barcelona) \\ Universidad de Barcelona
}

\section{INFORMACIÓN DEL ARTÍCULO}

\section{Historia del artículo:}

Recibido: 6 junio 2020

Aceptado: 15 septiembre 2020

On-line: 1 diciembre 2020

\section{Códigos JEL:}

F18

H51

I18

H75

Palabras clave

Epidemias

Cordones sanitarios

Comercio y contrabando

\begin{abstract}
R E S U M E N
Las medidas de resguardo sanitario, y especialmente las más radicales como son los cordones sanitarios, han sido normalmente consideradas contrarias a los intereses comerciales y, en consecuencia, negativas para la economía en general. Sin embargo, los países del sur de Europa, por tradición histórica, geografía e incluso por disponibilidades presupuestarias, no tenían otra opción que adoptar medidas de cuarentena, siguiendo los criterios acordados en las conferencias sanitarias internacionales, si querían seguir participando en el sistema internacional de comercio. De hecho, estas medidas restrictivas no supusieron un freno al crecimiento comercial como el caso de Mallorca evidencia, ya que resultaron ser un arma formidable de las nuevas autoridades liberales para disciplinar a la población y atacar frontalmente el contrabando que, además de suponer una amenaza para la salud, contravenía el orden social burgués, el Estado nación e, incluso, determinados aspectos del capitalismo.
\end{abstract}

@ 2020 Asociación Española de Historia Económica

\section{JEL classification:}

\section{F18}

H51

I18

$\mathrm{H} 75$

\section{Keywords:}

Epidemics

Cordons sanitaires

Trade and contraband

\section{Epidemics and (il)licit trade in Southern Europe: Mallorca, nineteenth century}

\begin{abstract}
A B S T R A C T
The measures of sanitary watch, and especially the more radical ones such as cordons sanitairies, have usually been considered to be contrary to commercial interests and therefore negative for the economy in general. However, the countries of southern Europe, due to historical tradition, geography and even budget availability, had no other option than to adopt quarantine measures, following the criteria agreed at the International Health Conferences, if they wanted to continue participating in the international trade system. In fact, these restrictive measures did not stop the growth of trade, as the case of Mallorca shows along the 19th century. They were a formidable tool of the new liberal authorities to discipline the population and attack contraband, which, in addition to being a threat to health, contravened the bourgeois social order, the nation state and even certain aspects of capitalism.
\end{abstract}

@ 2020 Asociación Española de Historia Económica

\footnotetext{
* Autor de correspondencia. Correo electrónico: pere.salas@uib.es

Nota: Quisiésemos agradecer los comentarios y las recomendaciones de los revisores/as y editores/as. Sin lugar a duda, han contribuido a la mejora del artículo.
} 


\section{Introducción}

Las medidas de resguardo sanitario, y especialmente las más radicales como son los cordones sanitarios, han sido normalmente consideradas contrarias a los intereses comerciales y, en consecuencia, negativas para la economía en general. Este hecho se puso de manifiesto en el transcurso del siglo XIX, cuando a causa de la irrupción de nuevas y viejas amenazas epidémicas en Europa (peste, fiebre amarilla y cólera) y en unos momentos de creciente globalización económica, el relanzamiento del sistema de cuarentenas fue visto como un ataque al libre comercio, fundamentalmente por parte de las autoridades británicas (Harrison, 2006, 2012) $)^{1}$. De hecho, el objetivo principal de las conferencias internacionales de sanidad iniciadas en 1851 en París fue la creación de un primer consenso internacional (entiéndase europeo) para racionalizar la aplicación de cuarentenas, que compatibilizasen la salvaguarda de la salud y el crecimiento del comercio internacional (Huber, 2006; White, 2020; Barona y Bernabeu, 2008; Rangel de Almeida, 2012).

Estas conferencias también tuvieron por objetivo frenar el uso encubierto del resguardo sanitario como arma diplomática y proteccionista (Harrison, 2006). Progresivamente, la mayoría de países dejó de lado las medidas aislacionistas en pro de una aproximación al sistema inglés (Maglen, 2014), que preveía la realización de inspecciones sanitarias a los barcos llegados a puerto, lo que sustituía, al menos parcialmente, la aplicación de cuarentenas. Pero esto no significaba lo mismo para todos los países. Como ha destacado Peter Baldwin (1999), el dominio global que ejercía Gran Bretaña le permitía disponer de territorios bajo su control en el propio Mediterráneo, donde hacían escala y cuarentena las personas y mercancías procedentes de lugares sospechosos, con lo cual el territorio metropolitano se podía liberar de este tipo de medidas estrictas a cambio de imponer un sistema de inspecciones sanitarias en los puertos. Por supuesto, los países del sur de Europa, por tradición histórica, geografía ${ }^{2}$ e incluso por disponibilidades presupuestarias ${ }^{3}$, no tenían otra opción que adaptar directamente medidas de cuarentena si querían seguir participando en el sistema inter-

\footnotetext{
${ }^{1}$ Debe añadirse que la oposición a las cuarentenas no se limitaba a los grupos mercantiles; también tenía implicaciones sociales, políticas, históricas y científicas, además de los médicos que seguían la teoría miasmática. También cabe considerar los costes y retrasos que ocasionaban a todos aquellos que viajaban regularmente, muchos de ellos personas influyentes en los respectivos estados (Harrison, 2006).

${ }^{2}$ Concretamente, Peter Baldwin (1999, p. 212) afirma que "the importance of geography is revealed in the basic split between the Mediterranean countries, in close contact with the Oriental founts of cholera, and the Atlantic nations at a further remove. The division between Atlantic and Mediterranean Europe separated nations afraid of epidemics that threatened directly from the Orient from those for whom the disease became a problem mainly once it had invaded Europe itself".

${ }^{3}$ Igualmente, Baldwin introduce el concepto de administrative capacity, al afirmar que la adopción de un determinado tipo de medida sanitaria se debía también al «extent to which nations had the bureaucratic, fiscal and statutory wherewithal -broadly speaking the state power- to enact the protective measures chosen" (ibid., 236). De esta forma, las cuarentenas serían más económicas que la gran inversión en infraestructuras higiénicas que necesitaban las ciudades europeas del ochocientos, tal como demandaban los higienistas, además de ser una solución urgente e inmediata. Los casos extremos que presenta el autor serian Grecia y Turquía, pero no cabe duda que países como España e Italia también participarían de estos presupuestos en buena medida. Sobre este tema véase también Eugenia Tognotti (2013).
}

nacional de comercio. La influencia europea sobre su periferia marcó otro hecho importante: la imposición de este sistema fuera de Europa, en las zonas y países situados en las principales rutas comerciales, como era el caso del Imperio otomano y Egipto (Ersoy, Yuksel y Aslihan, 2011; Slack, 2012).

España participó en las conferencias internacionales defendiendo la cuarentena, aunque adaptándose a los criterios de racionalización y relajación que se iban imponiendo paulatinamente (Barona y Bernabeu, 2008; Cuñat, 2014; Mateos, 2005). La primera ley general de sanidad promulgada en 1855 da buena prueba de ello, al centralizar la sanidad marítima, eliminando la capacidad de actuación que tenían las autoridades locales sobre la aplicación de cuarentenas y cordones, pero ni mucho menos eliminando este tipo de actuaciones. De esta manera, el sistema se basaba en la expedición de patentes limpias o sucias en los puertos de origen de los buques como se establece en el capítulo VIII de la ley.

Esta premisa también la deberían cumplir los propios países europeos, especialmente aquellos situados en la ribera mediterránea, con menos recursos económicos para implementar otro tipo de medidas. Así, comercio y sanidad deben ser considerados como elementos indispensables para la construcción del Estado nación en Occidente, en una época de creciente imperialismo y expansión del capitalismo. El nuevo Estado liberal necesitaba justificar un renovado control del territorio mediante el ejercicio de una gobernabilidad que asegurase tanto el crecimiento económico como el buen estado de salud de la población. En este punto, el contrabando emergía como un enemigo que batir de primer orden, ya sea por la detracción de recursos fiscales como por la ruptura y desacreditación del sistema de cuarentenas que suponía.

En este artículo analizaremos cómo las autoridades españolas, entre ellas las provinciales y locales, encararon este tipo de problemáticas en Mallorca durante el siglo xix. Es decir, de qué modo la política de resguardo sanitario se fue adecuando al aumento de tráfico de mercancías y de pasajeros de la época, tanto legal como ilegal, teniendo presente que los puertos de la isla, especialmente el de su capital, se incardinaron completamente en el proceso de internacionalización aludido, un proceso paralelo e inseparable de la creación del Estado liberal español. En este sentido, nos proponemos demostrar cómo el control epidemiológico $-\mathrm{y}$ las restricciones a la libertad que conllevaba- fue, por una parte, un aspecto más de la creación del Estado nación y, por otra, resultó imprescindible para asegurar el buen estado de salud de la población y el desarrollo económico. Una circunstancia que en pleno siglo xxI, a raíz de la actual pandemia de COVID-19, parece haberse olvidado.

Pensamos que un estudio regional como el que presentamos es la única forma de conocer la puesta en práctica de un sistema fuertemente centralizado, aunque ejecutado en buena parte por actores locales. El caso mallorquín nos ayudará a conseguir nuestros objetivos, no tanto por su especificidad, sino por ser representativo y significativo de una provincia del sur de Europa, expuesta al peligro epidémico de las regiones circundantes y con una importante actividad comercial (Terrades, 1987; Serna y Pons, 2000).

Concretamente utilizaremos fuentes municipales y provinciales, como son las actas de los ayuntamientos de un conjunto de localidades características y complementarias de la realidad mallorquina como son Alaró (AMAl, Archivo Municipal de Alaró), Alcúdia (AMA, Archivo Municipal de Alcúdia), Binissalem (AMB, Archivo Municipal de Binissalem), Llubí (AMLl, 
Archivo Municipal de Llubí), Pollença (AMP, Archivo Municipal de Pollença) y la capital de las Baleares, Palma (AMPa, Archivo Municipal de Palma). Además, se ha analizado la documentación relativa al establecimiento de los cordones sanitarios que abarca todo el siglo xix, depositada en el Archivo General del Consell de Mallorca (AGCM), que recoge los fondos de la antigua Diputación. Información similar, aunque mucho más puntual, proviene del Gobierno Civil, actualmente custodiada en el Archivo del Reino de Mallorca (ARM). También ha sido de gran interés la información aparecida en los boletines oficiales (BOP, Boletín Oficial de la Provincia y BOPB, Boletín Oficial de la Provincia de Baleares) o en la misma prensa de la época. Asimismo, se ha consultado documentación específicamente sanitaria, como es la generada por las diferentes juntas de Sanidad (locales y provinciales), que en algunos de los ayuntamientos mencionados aún se conserva. En nuestro caso, se ha analizado este tipo de documentación para el municipio de Pollença para el periodo 1784-1870. Su interés estriba en que no solo ofrece información local, sino que también reúne en buena parte las obligaciones en materia sanitaria que recibieron los municipios en esta época y, en ocasiones, el seguimiento que los ayuntamientos hacían de las mismas.

A continuación, el artículo se organizada en dos apartados dedicados a mostrar la importancia de las medidas de aislamiento para la preservación del comercio y cómo estas servían para la lucha contra el contrabando, a su vez que contribuían a las arcas del Estado y se preservaba la salud de los ciudadanos. Concluimos este estudio con una discusión final.

\section{El resguardo sanitario como protección del comercio}

La legislación de la sanidad marítima en España corría a cargo del Estado, que organizaba el marco de referencia para los Gobiernos provinciales y municipales, los cuales tenían la responsabilidad de gestionar este servicio por medio de sus propias instituciones y recursos. Si bien esta caracterización podría ser válida para todo nuestro período de estudio, hasta la creación de la ley general de sanidad de 1855 la autonomía de las instituciones periféricas, con una legislación en buena parte heredera del setecientos, fue aún mayor (Navarro y García, 2001). Por otra parte, el escaso avance de la medicina en el período de estudio determinó una forma de actuar ecléctica, perfectamente visible en el caso de Mallorca, entre las propuestas ambientalistas y contagionistas, es decir, entre medidas de tipo higiénico ambientalistas y las basadas en el resguardo sanitario (Pujadas y Canaleta, 2010).

En este contexto, al contrario de lo que cabría esperar, en Mallorca el número de puertos habilitados al comercio también aumentó. Así, la situación era opuesta a la de 1720 cuando se cerró el de Alcúdia en la parte septentrional de la isla, a raíz de la peste de Marsella. Este fue reabierto el 22 de agosto de 1779 por orden expresa de Carlos III, con la aseveración de «que en ningún tiempo, y por ningún pretesto, ni aun por el de peste, se volveria a cerrar el Puerto de esta ciudad de Alcudia» (Salas, 2010b, p. 138). Pocos años después se construyó un lazareto (Vidal, 2010; Alemany, 2001). Paralelamente se habilitó el puerto de Sóller -en el noroeste de la isla-, que tenía permitido incluso la exportación de cítricos al extranjero. Obviamente también tenía un lazareto y las infraestructuras necesarias para realizar la cuarentena.

Ciertamente, el puerto de Palma fue el único de las Baleares que en el Reglamento de Puertos de 1852 fue considerado de interés general de primer orden, siendo el resto de interés local de segundo orden, situación que se ratificó, a grandes rasgos, con la Ley de Puertos de $1880^{4}$. En la capital también había un lazareto, que se reformó en $1857^{5}$ y se amplió después del brote de cólera de 1865 . De todas formas, el establecimiento de referencia en esta materia estaba situada en la isla de Menorca, concretamente en el puerto de Maó. Este lazareto se trataba de una institución sanitaria al servicio del tráfico mercantil $^{6}$, que permitió tener abiertos los canales comerciales de Mallorca con aquellas destinaciones sospechosas e incluso "sucias». Así, la ciudad de Palma, el principal centro comercial de las Baleares, tenía las ventajas de tener un lazareto de gran importancia cerca, pero sin padecer sus potenciales consecuencias ${ }^{7}$. Además de lo apuntado, a partir de 1867 se establecieron las inspecciones sanitarias portuarias según lo propuesto en la Ley de Sanidad de 1855 , lo cual implicaba que en cada uno de los puertos había médicos o inspectores sanitarios, encargados de vigilar que los buques entrasen con las respectivas patentes limpias.

A grandes rasgos este era el sistema de resguardo ordinario, pero fácilmente se modificaba al aparecer un peligro epidémico en el entorno geográfico próximo, que podemos hacer extensible a los países del Mediterráneo occidental. Entonces la sanidad exterior se supeditaba a la formación de cordones marítimo-terrestres a lo largo de todo el litoral de la isla. Se trataba de medidas excepcionales de aislamiento, promovidas por las autoridades provinciales, pero ejecutadas por el ejército, que contó con el concurso de civiles armados hasta 1880 y del apoyo logístico y económico de los ayuntamientos durante todo el período. En la isla de Mallorca se levantaron un total de veintiocho cinturones en el litoral entre 1787 y 1899 . Además, en 1820, con motivo de la peste de Levante (de los municipios de Artà, Capdepera, Son Servera y Sant Llorenç), y 1821, con la fiebre amarilla declarada en Palma, se procedió al confinamiento de la zona afectaba a cargo del ejército y civiles armados y al acordonamiento de cada población a cargo de los propios ayuntamientos $^{8}$. Es interesante remarcar que la mayoría de municipios siguieron actuando de este modo después de la promulgación de la Ley de 1855 , que eliminaba este tipo de iniciativas de las autoridades locales e, incluso, suponía contravenir las órdenes expresas del gobernador, como ocurrió durante el cólera de

\footnotetext{
${ }^{4}$ Básicamente, los puertos de interés general de primer orden se diferenciaban de los de interés local en que la Administración central garantizaba el pago de las obras y la limpieza que este requiriese, además de contar con la capacidad de exportación e importación de mercancías.

${ }^{5}$ En el Boletín Oficial Balear publicado el 01-12-1857.

${ }^{6}$ Según Alemany (2001, p. 160) hasta el año 1855 realizaron cuarentena en el lazareto de Maó 7184 barcos, 87349 pasajeros y 225806 tripulantes, mientras que durante todo el período de funcionamiento, es decir, entre 1817 y 1917, dio servicio a casi 14000 buques.

7 Por ejemplo, durante el cólera de 1865, que afectó gravemente la ciudad de Palma, el 12 de agosto la Junta de Sanidad Provincial de Sanidad acordó que los buques con patente sucia, en primer término solo los procedentes de Marsella y Valencia, fuesen a purgar la cuarentena en el lazareto de Maó (Salas y Pujadas, 2016, p. 197).

${ }^{8}$ Aunque los ayuntamientos normalmente no necesitaban motivaciones especiales para levantar sus propios cordones cuando se declaraba un foco epidémico en la isla, sí que recibían instrucciones de la Junta Superior de Sanidad al respecto, como por ejemplo en la circular de 13 de setiembre de 1821, en la que se estipulaba que debían establecer un lazareto exterior donde debían pasar diez días todas las personas procedentes de Palma entre otras medidas (AMP-Sanitat-Ordres, 1681).
} 
Palma de $1865^{9}$. Esto es indicativo de una clara predisposición a favor de estas medidas cuando el peligro apremiaba, como también se ha visto en el caso italiano (Tognotti, 2013) ${ }^{10}$.

Asimismo, es interesante remarcar que también existían motivaciones económicas a favor del contagionismo. Es decir, la única forma de mantener el comercio con los espacios infectados era aislándolos mediante un cordón sanitario, tanto en el ámbito exterior como local. Esta realidad fue evidente a raíz del episodio de fiebre amarilla de la capital en 1821, cuando los campesinos solo reemprendieron el tráfico de productos de primera necesidad con la ciudad una vez esta se acordonó y se crearon puntos específicos y reglamentados para el intercambio, y aun así se tuvieron que emplear medidas coercitivas ${ }^{11}$.

En 1865 ante la repetición de la situación, la Comisión Permanente de Salubridad Pública, formada por individuos de la Junta Municipal de Sanidad de Palma y de la Junta Provincial, expresó el 18 de septiembre la conveniencia para «Palma y villas de Mallorca el establecimiento de un cordón sanitario en los alrededores de la ciudad, como el establecido en 1821, interpretando el deseo de la mayoría de los habitantes de la isla». Esta aseveración se vio reforzada por la prensa, que además justificaba el aislamiento por ser una medida que "favorecía a numerosas familias que no podían encontrar alimentos sino a precios fabulosos» (Llabrés Bernal, 1966, p. 316; Salas y Pujadas, 2016). No es de extrañar que las juntas de Beneficencia y Sanidad del Ayuntamiento hicieron una dramática petición conjunta a favor del acordonamiento completo de la ciudad para, de esta forma, salvar el comercio con el resto de la isla. Esta demanda dice así:

Consideraba que debía tenerse presente otra calamidad, no menos espantosa, que estaba de cerca amenazándonos; esta era la cuestión de subsistencias: que la autoridad local debía ante todo atender á que estas no faltasen en estos aciagos momentos, y que el único medio para conseguirlo, si por desgracia este estado de cosas continua por algún tiempo, era el inspirar confianza á los pueblos circunvecinos, á fin de que por si solos levantasen los cordones y cuarentenas que han impuesto a nuestras procedencias y á las de los demás pueblos de la isla y asegurándose ellos mismos de que nosotros quedamos convenientemente aislados y apartados de su comercio que la escasez de comestibles que en la actualidad deja ya sentirse en la capital ${ }^{12}$.

Como era de esperar, con motivo de la declaración de fiebre amarilla en Palma en 1870, el resto de municipios volvieron a crear sus propias medidas de resguardo a fin de darse confianza mutua y acceder a comerciar con la capital ${ }^{13}$. En otras pala-

\footnotetext{
${ }_{9}$ Circular del Gobierno de la Provincia, 29 de agosto de 1865, en BOPB, núm. 5129, 30 de agosto de 1865, y núm. 5132, 25 de septiembre de 1865. 10 Para profundizar sobre este tema, véase Salas y Pujadas (2018) o Pujadas y Salas ( 2018).

${ }^{11}$ El 25 de setiembre los municipios recibieron el «Reglamento que deberá observarse en el mercado de la puerta de S. Antonio", uno de los puntos tradicionales de acceso a la ciudad por parte de los campesinos.

12 AMPa-FP 1514/VII. La cursiva es nuestra.

${ }^{13}$ Sin realizar una investigación exhaustiva de todos los municipios, tenemos documentados acordonamientos locales a partir de octubre de 1870 en Alcúdia, donde se establecen cinco días de observación para las personas y tres para los géneros procedentes de Palma (AMA-Actas municipales de 30-10-1870); así como en Binissalem (AMB, 19-11-1870), Alaró (AMAl-Actas municipales, 10-11-1870) o Inca (AMAl-Actas municipales, 22-11-1870). En la comarca de Levante, por ejemplo, se acordó colocar puestos de vigilancia que abarcara la entrada en los
}

bras, en ausencia de alternativas científicas la única forma de asegurar el comercio entre la ciudad y su hinterland rural (realmente el resto de la isla) era mediante la aplicación de medidas avaladas por la medicina del momento y la experiencia histórica, entre las cuales ocupaban un lugar destacado las cuarentenas y los cordones sanitarios.

Las tensiones comerciales entre Palma y la "Part Forana» se reproducían por culpa del cierre de todos los puertos locales de Mallorca y la redirección del tráfico marítimo hacia la capital, el único puerto que quedaba abierto en la isla, aunque el de Maó sí que seguía en funcionamiento por razones obvias. En el caso de Alcúdia, ni siquiera le valió la disposición citada de Carlos III. De hecho, ante la amenaza de peste en 1794 ya fue clausurado junto al de Sóller. ${ }^{14}$ En 1810, a raíz de la fiebre amarilla detectada en Cartagena se dio orden "a los Bayles de las Villas marítimas incluso el de Alcúdia, para que estén con la mayor vigilancia, sin consentir que se admita en sus fondeaderos, puertos ni calas las embarcaciones que vengan de fuera Reyno, obligándolas a todas que vengan al Puerto de esta Capital [Palma] en donde serán examinadas con el más escrupuloso cuidado, para admitirlas o negarlas su entrada» ${ }^{15}$. La historia se repitió prácticamente en todas las ocasiones que se presentó una alarma similar, como en 1796, 1810, 1813 -al declararse la peste en Malta-, o 1838, bajo la amenaza del cólera ${ }^{16}$.

A pesar de la reiteración de este tipo de disposiciones durante la primera mitad del siglo, ninguno de los puertos locales fue cerrado permanentemente. Por supuesto, esto suponía mantener los controles sanitarios, incluidos sus lazaretos. Además, el hecho de que la comunicación de Mallorca con Menorca se hiciese habitualmente vía Alcúdia dio un valor añadido al puerto de esta localidad. De esta forma, si bien en los momentos de amenaza epidémica el comercio se centralizaba en Palma, en ocasiones en que esta se vio afectada ocurría la circunstancia contraria. Por ejemplo, en 1821, cuando la capital sufrió la referida epidemia de fiebre amarilla se cerró su puerto además de establecer un cordón sanitario interior que rodeaba el núcleo urbano, como hemos visto. Ante la falta de auxilios y víveres en toda Mallorca fue la misma Junta Provincial de Sanidad la que pidió a la Diputación Provincial «la indispensable necesidad la habilitación provisional de alguno de los dos puertos de Alcúdia o Sóller y aun el que se hiciese estensiva al comercio con el extranjero». Y aunque en principio la Diputación se decantaba por el de Sóller, realmente se habilitaron ambos. Evidentemente, este hecho tenía importantes implicaciones comerciales. Así, ante la persistencia del cierre de tráfico marítimo con Palma en enero de 1822, el presidente de la Junta Suprema de Sanidad del Reino comunicó a su homónima de Barcelona que la epidemia estaba circunscrita a la capital y que, por tanto, los buques procedentes «de las otras referidas islas se admitan sin restricción a libre plática y comercio y que los de Alcudia y Sóller de Mallorca en la clase de su habilitación o comercio, se reciban bajo el concepto de patente sospechosa». De hecho, existe constancia de que en 1822 la aduana de Alcúdia funcionó a pleno rendimiento, ya que el Ministerio de Hacienda tuvo que alquilar

municipios de Artà, Son Servera y Capdepera (AMC-Actas municipales, 1283, 30-09-1870).

${ }^{14}$ AMP-Sanitat-Ordes, 2899.

${ }^{15}$ La Antorcha, n. ${ }^{\circ}$ 3, f. 35, Biblioteca Virtual de Prensa Histórica.

${ }^{16}$ Estos datos nos han sido facilitados por el investigador Antoni Domingo Pons. 
unos almacenes supletorios. Ahora bien, cuando la epidemia remitió, Palma quiso recuperar el monopolio comercial con el extranjero, cosa que consiguió en diciembre de $1826^{17}$.

De nuevo, vemos como las restricciones al comercio por motivos sanitarios eran imprescindible para mantener comunicadas las Baleares con el exterior, y si no era a través de la capital, lo sería gracias a los puertos habilitados de Sóller y Alcúdia. A su vez, como hemos observado, esto también implicaba severas medidas de control interno para evitar la expansión de la epidemia al resto de la isla. Esta situación se consolidó y amplió durante la segunda mitad de siglo, cuando se añadieron a los puertos locales mencionados los de Andratx (sudeste de Mallorca), Porto Colom (este), Manacor (este), Capdepera (levante) y Pollença (norte), todos ellos dotados de sus respectivas aduanas y un mínimo control sanitario. En Alcúdia en 1861 se reformó su lazareto y en 1885 fue declarado de interés general de segundo orden ${ }^{18}$. Evidentemente, el comercio exterior estaba fuertemente centralizado en Palma, pero el comercio de cabotaje, al menos entre los puertos de la isla, se mantuvo incluso durante los momentos de acordonamiento de la isla, reflejo de una cierta relajación de estas medidas en comparación con la primera mitad de siglo. Así, en agosto de 1867 se permitió el comercio de cabotaje entre los distintos puertos de la isla, «siempre que vayan autorizados por la Capitanía ó Ayudantía del puerto de su respectiva matrícula». Para que esta autorización tuviese lugar los alcaldes debían disponer «lo conveniente, en la inteligencia que será tratado como sospechoso el buque de esta clase que no lleve los papeles en toda regla» ${ }^{19}$.

En otro orden de cosas, era vital integrarse en los canales de información de la época y actuar en consecuencia. Las noticias llegaban de forma oficiosa gracias a las tripulaciones de los buques mercantes o la prensa. A otro nivel, la información circulaba a través de los boletines oficiales y la red consular en el extranjero o, en sentido inverso, gracias a los cónsules radicados en Mallorca. Por ejemplo, la Junta de Sanidad de Palma recibió el 29 de junio de 1813 la noticia por parte del vicecónsul de Malta de la presencia de peste en aquella isla. Entonces, previendo el peligro a causa de las intensas relaciones comerciales existentes con Mallorca, la Junta mandó el levantamiento de un cordón, señalando expresamente que se hiciese de la misma forma que el año anterior, cuando se había conseguido evitar la entrada de la fiebre amarilla. De esta forma se protegía del comercio con Malta y, al mismo tiempo, se creaba confianza con las otras naciones que comerciaban con Mallorca.

De todas estas noticias dieron buena cuenta los boletines oficiales de la provincia a partir de 1834, dando a conocer sistemáticamente la realidad sanitaria de las diversas plazas mercantiles del mundo. Así, se ponían sobre aviso a las instituciones portuarias y se extremaba la vigilancia, especialmente de las naves procedentes de ciudades o zonas consideradas peligro$\operatorname{sas}^{20}$. A la inversa, el conocimiento del estado de salud de las Baleares en general y de Mallorca en particular, así como las

\footnotetext{
${ }^{17}$ Diario Balear, n. 992 y Diario Constitucional, Político y Mercantil de Palma n.. 30, 30-05-1822 (Biblioteca Virtual de Prensa Histórica).

${ }_{18}$ AMA-Actas municipales, 6-10-1861 y Soler (2004, p. 142).

${ }^{19}$ AGCM-Establiment del Cordó Sanitari S-III-249-33, 13-08-1867.

${ }^{20}$ Por ejemplo, en el BOP de 17-03-1854 se informa que el cólera ha desaparecido de la ciudad de Liverpool, mientras que en el BOP de 31-101896 se da la noticia de la aparición de la peste bubónica en Calcuta y en el de 2-09-1899 de su desaparición. Y a veces se trataba de desmentir rumores, como en el BOPB de 31-07-1884 para el caso de España.
}

medidas tomadas en función de peligros externos o internos a la isla, eran rápidamente difundidos fuera de la isla gracias al tráfico marítimo, la prensa y los cónsules extranjeros en Mallorca. Por ejemplo, durante la peste de Son Servera de 1820, la Comisión Provincial de Salud de Palma comunicaba puntualmente a su homóloga de Barcelona las actuaciones tomadas contra la epidemia, en especial todo lo referente al sistema de aislamiento implantado, además de los datos sobre su extensión y evolución. Periódicos como Diario Constitucional Político y Mercantil de Barcelona se hicieron eco de la crisis que se vivía en la isla y de cómo afectaba a las relaciones comerciales. Además, el consulado francés en Baleares informaba a su país de lo que acontecía en la isla.

En este sentido, resultan de gran interés los informes que enviaba periódicamente el vicecónsul François Abraham sobre Mallorca a las autoridades de Marsella y de Toulon vía Maó (Menorca), donde estaba radicado el cónsul, sobre la evolución de la enfermedad y las medidas puestas en práctica para controlar su expansión. Después de unos primeros informes muy críticos, donde se subraya la situación caótica que se vivió, a partir de mediados de junio de 1821 destacó la gran labor organizativa de las autoridades isleñas y la prolongación en el tiempo de las medidas preventivas, incluso cuando habían cesado los efectos de la peste. Evidentemente, como señala el mismo Abraham, la actividad comercial de Mallorca quedó muy mermada, pero aun así no se interrumpió con los puertos peninsulares de Barcelona, Tarragona, Alfaques y Palamós gracias a las precauciones sanitarias llevadas a cabo. El propio cónsul de Maó en carta de 9 de agosto dio la noticia de que desde finales de julio se permitía a los barcos del país salir en dirección a los puertos donde hubiese lazareto y, concretamente, dos de ellos aprovecharon la circunstancia para dirigirse a Marsella. Además, informaba de las circunstancias con las que zarpaban los buques $^{21}$. En definitiva, tan importante era actuar según el paradigma dominante de la medicina del momento como inspirar confianza a los potenciales socios comerciales.

Solamente a finales de siglo, cuando la bacteriología se impuso como nuevo paradigma científico, se cuestionó seriamente el modelo de resguardo aplicado hasta el momento. Esta noticia aparecida en el periódico liberal progresista de Palma, El Isleño, claro representante de los intereses comerciales de la ciudad, propone, siguiendo al periódico barcelonés La Vanguardia, abandonar las medidas de aislamiento y substituirlas totalmente por el «modelo inglés», ya que

el sistema cuarentenario en lo que se refiere á las mercancías procedentes directa ó indirectamente de la India es una pura ilusión: si el algodón, los granos y demás substancias contumaces llegan infestadas á nuestras puertas, siendo vehículo del microbio de la peste, con seguridad de que nada sirve el Lazareto de Mahón, porque no hay modo humano de purificar y sanear las apretadas balas de materia textil ó los centenares de toneladas de un trigo, sin quemar las primeras y echar al agua las segundas. [...] Es preciso desengañarse: la única profilaxis urbana posible de las grandes epidemias consiste en el sanamiento y en las condiciones de las ciudades $^{22}$.

\footnotetext{
${ }^{21}$ Ministére des Affaires Étrangers, Paris (La Courneue), Correspondance consulaire et commercial, Palma-9 (1820-1835), Mahon 5 (1817-1821). Debemos las referencias de esta documentación a Isabel Moll, que, en parte ya fue publicada en Moll, Salas y Pujadas (2017).

22 El Isleño, de 01-02-1897.
} 


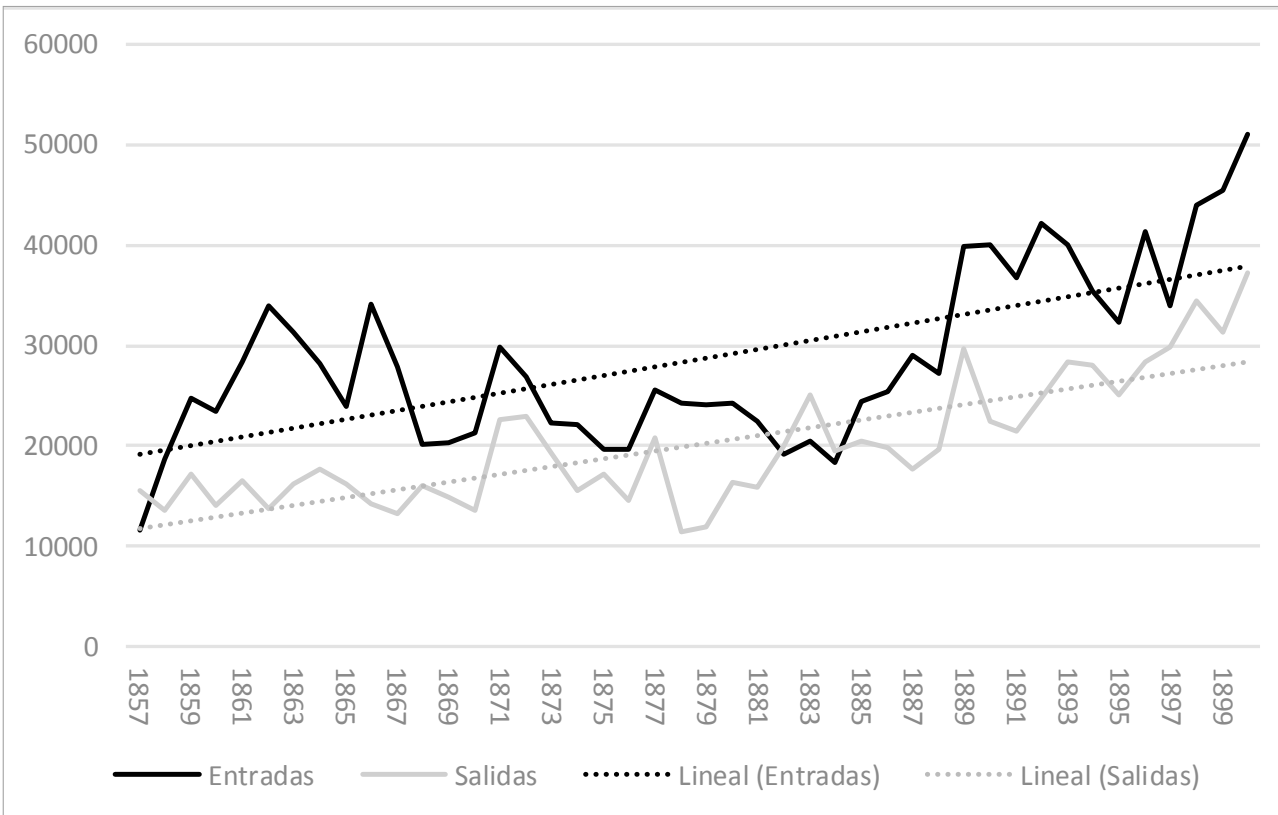

Gráfico1. Entradas y salidas de mercancías de los puertos de Mallorca, 1857-1900 (en kilogramos).

Fuente: elaboración propia a partir de los datos aportados por Carles Manera (2001, p. 387).
Pero este es el comienzo de otra historia.

Durante el ochocientos los intereses comerciales en los países mediterráneos, incluso en la segunda mitad de siglo, no rehusaron el sistema de cuarentenas, sino que lo adaptaron a sus propias expectativas. Esto quiere decir que ante la dicotomía entre libertad comercial y salud pública que se presentaba ante cualquier amenaza, se solían decantar por la segunda, ya que el desarrollo de una epidemia en territorio propio (o incluso ajeno) era más costoso, en términos humanos, pero también económicos, que las medidas restrictivas impuestas. Y, en cualquier caso, las empresas navieras tendían a recuperar rápidamente lo que habían perdido durante la $\mathrm{crisis}^{23}$. De hecho, en líneas generales asistimos a un incremento de los intercambios comerciales, como se colige de las entradas y salidas de mercancías del puerto de Palma en 1857 y 1900 (Manera Erbina, 2001, p. 387), y que se muestra en el gráfico 1. Es cierto, no obstante, que este incremento es mucho más acusado y sostenido a partir 1883 y que, en 1865, coincidiendo con el cólera en Palma, se produce un descenso de las entradas. Ahora bien, en ningún caso el factor epidémico impidió el tráfico comercial, y este, probablemente, se vio más influido por factores políticos y económicos que sanitarios. Incluso en 1870, año de la epidemia de fiebre amarilla en Palma, se produce un ligero repunte del tráfico.

\section{Contra un enemigo contumaz y querido: el contrabando}

Había otros motivos para abogar a favor de las mediadas contagionistas, como por ejemplo de tipo fiscal, disciplinario, de política exterior e incluso nacionales. Todos ellos confluyen en la lucha contra el contrabando.

En primer término, se debe poner de relieve que tanto el comercio legal como el sistema de cuarentenas suponía una fuente de ingresos que el Estado no podía permitirse prescindir.

\footnotetext{
${ }^{23}$ De esta forma, con el estudio de caso de Mallorca avalamos la propuesta planteada por Peter Baldwin (1999, p. 204).
}

Las tasas, derechos o arbitrios - tanto generales como específicos- devengados servían para asegurar su funcionamiento y las reformas que permitieron su adecuación a las exigencias del creciente tráfico marítimo, así como al aumento de dimensiones y de calado de los buques. Como en el resto del sistema impositivo liberal, la tendencia fue la regulación y la uniformización de toda la carga fiscal. En 1851, cuando el Gobierno central se hizo cargo formalmente de los puertos, aún perduraba una gran amalgama de derechos y arbitrios, que se fue reduciendo en base a la imposición de una serie de tarifas generales, especialmente a partir del Decreto de 1 de junio de 1869, tales como el gravamen del derecho de entrada de buques según su tonelaje o la descarga de mercancías y pasaje, distinguiéndose entre navegación de cabotaje y de altura, así como de llegada forzosa. Por otra parte, se mantenían tasas especiales, como las de cuarentena, lazareto y del práctico (Soler, 2004, p. 132-133), que también habían sido contempladas por la ley general de Sanidad de 1855.

Este último punto resulta de gran importancia para los objetivos de este artículo, ya que los ingresos provenientes de las tasas sanitarias en los puertos españoles superaban ampliamente los costes del servicio (Bonastra, 2018, p 31). Este hecho cobró más importancia aún a partir del establecimiento de juntas de Obras Locales durante el Sexenio -concretamente, la de Palma fue creada oficialmente por Real Orden de 16 de agosto de 1872-. Estaban integradas por representantes del Ayuntamiento de Palma, de la Diputación y de la Junta de Agricultura, Industria y Comercio, además de dos comerciantes, dos navieros y dos propietarios; por supuesto también formaban parte de la misma el comandante de Marina y el ingeniero de caminos, canales y puertos de la provincia, y estaba presidida por el gobernador civil. Era evidente que el sector mercantil estaba sobrerrepresentado, sobre todo si tenemos en cuenta que en no pocas ocasiones dominaba el Ayuntamiento y la Diputación.

Otra derivada no estrictamente sanitaria del sistema de cuarentenas era un proteccionismo encubierto. Curiosamente, este fue cada vez más relevante a medida que los Gobiernos liberales, concretamente desde la reforma arancelaria de Ale- 
jandro Mon en 1845, iban avanzando lentamente hacia el librecambismo, hecho que se acentuó gracias a la ley de Laureano Figuerola publicada en 1869 (Tortella, 1994). Esto coincidiría precisamente con la fiebre reguladora experimentada a raíz del Real Decreto de 24 de abril de 1867, por el cual se establecía que todos los puertos habían de actuar de facto como lazaretos, al menos de observación, añadiéndose el 26 de abril otro decreto por el cual se regulaba el sistema de servicios sanitarios marítimos (Bonastra, 2018, p. 30).

Un tercer aspecto, tan importante como los dos anteriores, hace referencia al carácter disciplinario del sistema de resguardo y, especialmente, a todo lo referente a los cordones sanitarios, una medida, no lo olvidemos, extraordinaria pero utilizada con una cadencia tan elevada en el transcurso del ochocientos que, en la práctica, cabe considerarla casi ordinaria. Los repetidos acordonamientos suponían una forma de medicalización militarizada de la vida con el pretexto de mejorar el estado de salud y, más concretamente, de evitar las crisis de mortalidad causadas por las epidemias. Esta formulación tenía a su favor una experiencia histórica considerada positiva, cuya expresión más reciente se situaba en el éxito que tuvo la contención de la peste en el Levante de Mallorca en 1820, además de estar avalada por la ciencia médica del momento.

De esta forma, la política sanitaria, incluida la coercitiva de resguardo, se convierte en un elemento más de la gobernabilidad liberal, que precisa del nuevo Estado para legitimarse. Como explica Patrice Bourdelais (2003), siguiendo a Michael Foucault, históricamente no ha habido mejoras sustanciales en la situación de salud de ningún país sin la formación de una administración intervencionista a través de cuerpos profesionales. Esto era producto de la voluntad de poder del Estado, pero también de la exigencia de mejores condiciones de salubridad por parte de la ciudadanía, que daba por asumidas las alteraciones de su modo de vida que en otras circunstancias serían consideradas intolerables (Foucault, 1991). Es decir, la población no solo es objeto de la ciencia, sino que también está compuesta por sujetos sometidos a nuevas prácticas disciplinarias de saber y poder que son interiorizadas de forma voluntaria (Campillo Meseguer, 2001, p. 36). Para nosotros, lo más interesante es que "la idea fundamental que subyace a esa noción de lo biopolítico es abandonar el concepto del poder desde el punto de vista de la represión, de la prohibición, para acercarse a él como productor de libertad que está en los mismos fundamentos del liberalismo, pero que no sería sino expresión y resultado de las técnicas de gobierno y respecto de las cuales el Estado es un correlato" (Serrano, 2017, p. 59).

En este sentido, el contrabando emerge como un factor fuertemente arraigado entre la población, pero potencialmente desestabilizador del Estado y de la sociedad; de ahí la imposibilidad de erradicarlo utilizando únicamente medidas represivas. Si popularmente no es considerado un delito, sino más bien un modo de subsistencia y una alternativa al poder establecido, las autoridades deben crear un discurso que consiga cambiar esta realidad para mantener el sistema político, sanitario y económico (Salas, 2010a). En la práctica el comercio ilegal merma el erario del Estado, los ingresos comerciales de las autoridades portuarias y disuelve el resguardo al esquivar la vigilancia sanitaria y convertir en porosas las fronteras e, incluso, el aislamiento de los cordones. De ahí que el Gobierno central y provincial complementarán la coerción con medidas publicitarias y pedagógicas como parte de la lucha antiepidémica. Se trata de una especie de coartada ideológica que tendrá como objetivo convencer a la ciudadanía de las consecuencias perniciosas, en el ámbito individual y colectivo, que conlleva el comercio ilegal. Es decir, el contrabandista no solo atenta contra el erario público, sino contra la vida.

De hecho, en la práctica y en la teoría, la adopción de cinturones sanitarios es presentada como una respuesta al comercio fraudulento, que no respetaba la legalidad ordinaria ni la extraordinaria, tanto en materia sanitaria como económica -derecho de aduanas, tasas especiales, etc.-. Lógicamente, las autoridades de la época durante el periodo que abarca nuestro estudio asociaran el establecimiento de los cordones sanitarios, y toda la pérdida de libertad, esfuerzo humano y pérdidas económicas que conllevaban, a la persistencia de los contrabandistas en burlar las prescripciones legales. Un primer ejemplo se produce en 1793, cuando se especifica que las rondas del litoral debían impedir «arrimar a parage alguno javega laud ni otro genero de embarcación que con descaro, poco temor de Dios del Rey y de la Causa Pública introducen tavaco de Brasil de Contravando con otras ropas susceptibles de contagio en el concepto de que quien lo consintiese será castigado con la mayor pena sin admitirsele menor escusa » ${ }^{24}$.

Realmente, el peligro epidémico facilitó la utilización de medidas represivas contra una actividad muy difícil de erradicar por culpa de su aceptación popular. Esto explica que el bando publicado el 29 de agosto de 1812 con motivo del peligro que representaba la fiebre amarilla, estableciese que los reos de contrabando fuesen condenados a muerte. En 1815 los municipios de la costa recibieron una circular para que extremasen la vigilancia de la costa para evitar la entrada fraudulenta de telas y algodones procedentes de Gibraltar, a causa de la fiebre amarilla que se padecía en aquella plaza ${ }^{25}$. En los siguientes años se sucederán este tipo de órdenes, donde el contrabando aparece como la causa explícita de la militarización de los cordones del litoral, como sucedió en julio de 1818 cuando se informa a los ayuntamientos de los cometidos «a que deben arreglarse los comandantes de las cuatro partidas de Tropa, que conforme a lo acordado por la Junta Superior de Sanidad de estas Islas, deberan destacarse á los puntos de la costa marítima que se les señalará, para impedir la comunicación clandestina de los buques que lleguen á ella con los de tierra, y la introducción de contrabandos» ${ }^{26}$.

En este contexto no es de extrañar que la introducción de la peste bubónica en Son Servera (1820) sea atribuida a un contrabandista ${ }^{27}$. Y que en 1821, ante el traslado de tropas de la costa al cordón interior que separaba la ciudad del resto de la isla, se exhorte a las autoridades locales para que procuren defender por ellas mismas las introducciones ilegales en las isla "unico conducto de los males que nos afligen $[. .].)^{28}$. O lo

\footnotetext{
24 AMP-Sanidad-Ordenes, 2899.

${ }^{25}$ AMP-Sanidad-Ordenes, 2899, 29-08-1812 y 5-05-1815, respectivamente. En este último caso la pena impuesta a las autoridades locales que no cumpliesen con su cometido era de diez años de presidio en África.

${ }^{26}$ AMP-Sanidad-Ordenes, 2899, 29-07-1818. La cursiva es nuestra.

${ }^{27}$ Realmente se desconoce como entró la epidemia en Mallorca, pero lo verdaderamente importante en este caso es que la acusación del contrabandista como vector de entrada de la más importante crisis sanitaria del siglo en Mallorca fue asumida por las autoridades de forma oficial.

${ }^{28}$ AMP-Sanidad-Ordenes, 1681, 13-09-1821. Proclamas que se volverán a repetir un año después para prevenir la entrada de la peste de Argel (AMPSanidad-Ordenes, 1681, 1-06-1822).
} 
que es lo mismo, el contrabando es presentado como la puerta de entrada de un peligro epidémico que se percibe como un auténtico cataclismo, después de la terrorífica experiencia de la peste del año anterior.

Como era de esperar, la aparición del cólera no hizo sino recrudecer la lucha contra el comercio ilegal, prueba que este no había conseguido erradicarse. Concretamente, en 1834 se afirma que

cuando el peligro de la invasión del cólera morbo que nos amenaza se aumenta de cada día, tiene el sentimiento esta Provincial de ver que se multiplica en casi todos los pueblos de su territorio el comercio de géneros de contrabando, introducidos en la isla fraudulentamente, burlando la vigilancia mas esmerada del cordón establecido. El progreso de este comercio tan pernicioso se debe á que las Justicias y Ayuntamientos olvidando de procurar el bien de sus cometidos, lo toleran y consienten en su distrito $[. . .]^{29}$.

Y por supuesto se debía evitar a toda costa que individuos acusados de contrabandistas pudiesen formar parte de los civiles armados que reforzaban el ejército en el cordón sanitario ${ }^{30}$.

A medida que avanza el siglo, con la amenaza del cólera a las puertas de la isla y el aumento de los intercambios comerciales, la redefinición del contrabando y el contrabandista como un vector epidémico se consolida aún más. Así, en 1854 los ayuntamientos recibieron una misiva del gobernador civil, el progresista José Miguel Trias, en la que se alertaba de la presencia del «cólera-morbo-asiático se halla en casi todos los pueblos marítimos de la costa oriental de Francia y otros mas interiores de aquella nación; que Barcelona se halla tambien invadida por esta plaga esterminadora del género humano, según las ultimas notícias recibidas de una manera oficial». Para continuar después con «la necesidad de reprimir el fraude y mas principalmente aquel que contenga materias contumaces de cualquier especie». Lo más interesante es que estas disposiciones son avaladas explícitamente por los saberes y recomendaciones de "los autores mas celebres de medicina legal en punto á medidas higiénicas», además de los médicos de la Junta Provincial de Sanidad, incluida la Sección de Medicina y Cirugía de la misma. Como un correlato de este discurso político-científico se especifican las medidas represivas que se han tomado, que empiezan con la amenaza de que todo aquel que infringiese el cordón sanitario sería considerado un malhechor malicioso que atenta contra la salud pública, que sería castigado con penas extraordinarias de presidio y hasta con la muerte si introdujese artículos contumaces de cualquier clase que sean ${ }^{31}$.

En 1865, en plena epidemia de cólera en la capital, la culpabilización del contrabando era mucho más creíble. Curiosamente, en estos momentos la relación entre fiscalidad y salud pública se pone de manifiesto de forma más explícita, cuando las autoridades sanitarias hicieron público que «acordaron ayer en la junta general que se establezca una vigilancia escrupulosa en las costas de la isla á fin de impedir los alijos de contrabando que en las presentes circunstancias, á mas de afectar

\footnotetext{
${ }^{29}$ AMP, Sanidad-Ordenes 1681, 26-10-1834.

30 «Procurará V. En cuanto sea posible que los primeros que lo desenpeñen sean personas de arraigo y responsabilidad, y excluirá deel á la gente de mal vivir y á los que tengan la tacha de contrabandistas (AMLlCorrespondencia, 26, 4-12-1849).

31 AMLl-Correspondencia, 26, 54-08-1854.
}

á los intereses del Tesoro, pudieran comprometer gravemente la salud pública» ${ }^{32}$.

$\mathrm{Al}$ año siguiente del brote de cólera padecido, este servía como recordatorio directo de la estrecha relación existente entre crisis sanitaria y contrabando. Es más, la justificación del nuevo cordón que se pretende establecer obedece a la única causa del comercio ilegal. Así, entre las medidas que adoptar per evitar una nueva epidemia se señala que "por necesidad ha de estar en el ánimo de todos» se incluye el establecimiento del cordon terrestre en las costas de esta isla "con el fin de evitar todo desembarque fraudulento en ellas» ${ }^{33}$. Una vez más, debemos reiterar que no se trataba de cerrar la isla al comercio en general. En disposiciones posteriores, se establece que debido a la presencia del cólera en determinadas zonas de Europa y otros enclaves, habrá que desviar al lazareto de Maó todos los navíos procedentes del sur de Francia, Marruecos y Argelia, extremar la vigilancia en la costa mediante el cordón que se había establecido y evitar el desembarque de todo tipo de géneros fraudulentos ${ }^{34}$.

Evidentemente, este tipo de medidas no sirvieron para erradicar totalmente el contrabando, pero la documentación consultada sugiere que el apoyo de la población a la represión contra el mismo tendió a aumentar ${ }^{35}$. Al menos esto es lo que indica la justificación a favor de un nuevo cordón en agosto de 1867, cuando ante la llegada del cólera al norte de Italia, tanto el Gobierno provincial como la preceptiva Junta de Sanidad, se hacen eco de «que la opinion pública reclama en semejantes circunstancias, como uno de los medios más eficaces de prevenir la importación del germen de aquella enfermedad por medio del contrabando, el cordón de vigilancia» ${ }^{36}$.

En fin, avanzado el siglo aún perduran el mismo tipo de exhortaciones, como las que encontramos en 1885 cuando la Junta de Sanidad vuelve a pedir a los ayuntamientos por enésima vez que vigilen la entrada de productos de contrabando, especialmente a los de Argel y de Inglaterra, extendiendo después la amenaza a los provenientes de las ciudades de Marsella y Orán. Además, se recuerda que la pena de muerte se cierne sobre los contrabandistas y los encubridores ${ }^{37}$. Paradójicamente, las alusiones a Francia y Gran Bretaña, dos de las grandes potencias comerciales del momento, nos hace pensar en la relación existente entre proteccionismo y medidas de cuarentena.

\section{Conclusiones}

Retomando nuestro punto de partida, es evidente que el sistema de cuarentenas e, incluso, los cordones sanitarios no supusieron un freno al crecimiento comercial, sino su única posibilidad en el contexto mediterráneo del siglo XIX, avalado por los acuerdos alcanzados en las conferencias sanitarias internacionales. Solo la imposición del paradigma bacteriano a

\footnotetext{
32 AGCM-Establecimiento del Cordón Sanitario S-III-249-33.

33 AMLl-Correspondencia, 27, 15-07-1866.

34 AGCM-Establecimiento del Cordón Sanitario S-III-249-33, 10-11-1866.

35 Se trata, por tanto, de una hipótesis que deberá ser comprobada en futuros trabajos centrados en esta materia.

${ }^{36}$ AGCM-Establecimiento del Cordón Sanitario S-III-249-33, 13-08-1867.

${ }^{37}$ AMAl-Actas Municipales, Sanidad, 1763, 1-01-1885 y AMLl Correspondencia, 29, 18-08-1885.
} 
partir de la década de los ochenta hizo cambiar la situación y convertir en obsoletas y contrarias al comercio este tipo de medidas. Ello no quiere decir que la política sanitaria no pudiese actuar como parte de una reactivación de políticas proteccionistas, acordes con la manera de proceder entonces de la mayoría de países de la época ${ }^{38}$.

En otro aspecto, durante el último tercio de siglo el incremento de la actividad comercial coincide con un importante plan de reformas del puerto de Palma. Y aunque no tengamos datos al respecto, es evidente que la política de resguardo sanitario, incluso el retorno al contagionismo que se produjo a partir de 1867, no impidió, sino todo lo contrario, la ejecución y financiación de las mismas, especialmente a partir de la constitución de la Junta de Obras del Puerto en 1872.

Paralelamente, la política de resguardo sanitario tuvo relativo éxito al reducir de forma considerable el impacto de las epidemias en Mallorca durante el siglo xix. Estas se restringen a la peste en 1820, el cólera de Andratx y Palma en 1854 y 1865, respectivamente, $\mathrm{y}$ a los brotes de fiebre amarilla de la capital en 1821 y 1870 (Moll Blanes, Segura y Suau Puig, 1983). Además, en ningún caso afectaron a la totalidad de la isla y no alteraron de manera importante la línea descendente de la mortalidad y el aumento de la esperanza de vida que se experimentaba en esta misma época, especialmente durante la segunda mitad de siglo. Tanto es así que las Baleares desde mediados del siglo xix eran la provincia española con la esperanza de vida más alta de España (Dopico, 1987; Bujosa Homar, Moll Blanes y Sureda, 2000; Muñoz Pradas, 2005 a, 2005b; Moll Blanes et al., 2014).

Por otra parte, no cabe duda de que el factor epidémico fue un arma formidable de las nuevas autoridades liberales para disciplinar a la población y para hacerle abandonar unos determinados hábitos considerados contrarios al orden social burgués y a la expansión del capitalismo y al fortalecimiento del Estado nación. No es casualidad que en España, como también en Italia, la salud pública estuviese encomendada al Ministerio de la Gobernación (Serrallonga Urquidi, 1996), instancia política que a su vez estaba encargada del mantenimiento del orden interno. Se podría decir que la sanidad de base científica que se va imponiendo durante el siglo xIx, ya sea en su carácter profiláctico o, también, en todo lo relativo al higienismo, asumirá una postura normativa, reflejada en la legislación y la práctica de la época, que autorizaba no solamente la distribución de consejos de salud, sino también el dictado y la imposición de estándares para las relaciones entre los individuos, ya sean morales como físicos, así como para regular todo tipo de intercambio y de compartimentación del espacio (Miller, 1987). De este modo, se trata de una imposición, violenta si cabe y ante la amenaza de la pena de muerte, pero justificada por la ciencia, que a su vez recaba convencimiento y colaboración de todos los habitantes.

La función de la sanidad pública decimonónica, por tanto, va más allá de la propia preservación de la salud individual. Sirve para reafirmar un determinado modelo de Estado, de sistema económico, donde el capitalismo comercial era de suma importancia, y de comportamiento social. Pero, lógica-

\footnotetext{
${ }^{38}$ Matizamos de esta forma la afirmación de autores como Deaton (2004) o Troesken (2015), que consideran que fueron importantes para el comercio las cuarentenas, pero ineficaces para frenar la entrada de epidemias.
}

mente, no solo es esto. En efecto, su discurso no hubiera sido creíble si no se hubiera conseguido disminuir el peligro epidémico. En general, esto supuso un factor más de legitimación de las administraciones públicas, tanto a nivel interno ${ }^{39}$ como externo. Es decir, se refrendaba una determinada forma de gobierno y se aseguraba su aceptación en las redes de comercio internacional, aunque, evidentemente, el siglo xx abriría otras formas de actuación que facilitaron aún más los intercambios y el crecimiento. Paradójicamente, el contrabando, pese a su pérdida de legitimación como consecuencia de las medidas de aislamiento, vio interrumpido su proceso de criminalización y, por los datos disponibles, repuntó en Mallorca durante buena parte del siglo $\mathrm{xx}^{40}$. Así mismo, la actual pandemia nos ha recordado la importancia del control epidemiológico para asegurar el progreso económico y social.

\section{Bibliografía}

Alemany, J., 2001. Els grans ports de les Balears. Ports de Balears. Lunwerg, Barcelona.

Baldwin, P., 1999. Contagion and the State in Europe 1830-1930. Cambridge University Press, Cambridge.

Barona Vilar, J. L. y Bernabeu-Mestre, J., 2008. La salud y el Estado. El movimiento sanitario internacional y la administración española (1851-1945). Publicacions de la Universitat de València, València.

Bonastra Tolós, J., 2018. Quarantine and territory in Spain during the second half of the nineteenth century, En: Chircop, J. y Martínez, F. J. (eds.). Mediterranean quarantines, 1750-1914. Space, identity and power. Manchester University Press, Manchester, pp. 17-46.

Bourdelais, P., 2003. Les épidémies terrassées. Une historie des pays riches. Éditions de La Martinière, París.

Bujosa Homar, F., Moll Blanes y I., Sureda, B., 2000. La avanzada transición demográfica en Mallorca: el caso de la mortalidad infantil. Boletín de la Asociación de Demografía Histórica, 18 (2), 125-146.

Cabrera, M., 2011. Juan March (1880-1962). Marcial Pons, Madrid.

Campillo Meseguer, A., 2001. La invención del sujeto. Biblioteca Nueva, Madrid

Cuñat Romero, M., 2014. Higiene, política y domesticidad en la España decimonónica: El higienista Monlau (1808-1871). European University Institute, Florencia.

Deaton, A., 2004. Health in an age of globalization, En: Collins, S. y Graham, C. (eds.). Brookings trade forum 2004: Globalization, poverty and inequality The Brookings Institution, Washington, D. C, pp. 83-110.

Dopico, F., 1987. Regional Mortality Tables for Spain in the 1860s. Historical Methods, 20, 173-179.

Ersoy, N., Yuksel, G. y Aslihan, A., 2011. International Sanitary Conferences from the Ottoman perspective (1851-1938). Hygiea Internationalis, 10, 53-79.

Ferrer Guasp, P., 2000. Joan March. Els inicis d'un imperi financer, 1900-1924. Edicions Cort, Palma de Mallorca.

Foucault, M., 1991. Governmentality, En: Burchell, G., Gordon, C. y Miller, P. (eds.). The Foucault Effect: Studies in Governmentality with Two Lectures by and an Interview with Michel Foucault. University of Chicago Press, Chicago, pp. 87-104.

Harrison, M., 2006. Disease, diplomacy and international commerce: the origins of international sanitary regulation in the nineteenth century. Journal of Global History, 1, 197-217.

\footnotetext{
${ }^{39}$ Legitimación derivada de su eficiencia en el control de la salud pública y, por tanto, de la preservación de la vida, en el sentido de aplicación de la ley natural apuntado por Locke (1991); pero también porque contribuye a conferir validez al orden político al que está sujeto una población dada (Weber, 1979).

40 Esta afirmación se basa en la inaudita importancia social y económica que asumió el contrabando durante los dos primeros tercios del siglo xx en Mallorca. El exponente principal del mismo no fue otro que Joan March Ordinas, como lo atestiguan los trabajos de Pere Ferrer (2000) o Mercedes Cabrera (2011). Ahora bien, debemos insistir en que se trata de una hipótesis que necesita ser validada con trabajos específicos referidos al siglo XIX.
} 
Harrison, M., 2012. Contagion: how commerce has spread disease. Yale University Press, Yale.

Huber, V., 2006. The unification of the globe by disease? The international sanitary conferences on cholera, 1851-1894. The Historical Journal, 49, 2, 453476.

Locke, J., 1991. Dos ensayos sobre el gobierno civil. Espasa-Calpe, Madrid.

Llabrés Bernal, J., 1966. Noticias y relaciones históricas de Mallorca: siglo XIX (1861-1870) (Vol. 4). Imprenta Alcover, Palma de Mallorca.

Maglen, K., 2014. The English System: Quarantine, immigration and the making of a Port. Manchester University Press, Manchester.

Manera Erbina, C., 2001. Història del creixement econòmic a Mallorca (17002000). Lleonard Muntaner, Palma de Mallorca.

Mateos Jiménez, J. B., 2005. Actas de las conferencias sanitarias internacionales (1851-1938). Revista Espanyola de Salud Pública, 79 (3), 339-349.

Miller, P., 1987. Domination and power. Routledge and Kegan Paul, London, New York.

Moll Blanes, I., Salas Vives, P. y Pujadas Mora, J. M., 2017. Vers une nouvelle modernité sanitaire: l'épidémie de peste de Majorque en 1820. Annales de Démographie Historique ("Le retour de la peste»), 2 (134), 125-149.

Moll Blanes, I., et al., 2014. La lluita per la vida. Administració, medicina i reforma sanitària (Mallorca 1820-1923). Gall Editor, Pollença.

Moll Blanes, I., Segura, A. y Suau Puig, J., 1983. Cronologia de les crisis demogràfiques a Mallorca. Segles XvIII-XIX. Institut d'Estudis Baleàrics, Palma de Mallorca.

Muñoz Pradas, F., 2005. Geografía de la mortalidad española del siglo xIx: una exploración de sus factores determinantes. Boletín de la AGE, 40, 269-310.

Navarro y García, R., 2001. Historia de la sanidad marítima en España. Instituto de Salud Carlos III Madrid.

Pujadas Mora, J. M. y Canaleta Safont, E., 2010. La actuación de la Real Academia de Medicina y Cirugía de Palma de Mallorca ante el peligro epidémico (Mallorca, siglo XIX). En: Perdiguero Gil, E. y Vidal Hernández, J. M. (eds.). La ciudadela de los fantasmas. Lazaretos y protección sanitaria en el mundo moderno. Institut d'Estudis Menorquins, Maó, pp. 49-64.

Pujadas Mora, J. M. y Salas Vives, P., 2018. Inland sanitary cordons and liberal administration in southern Europe: Mallorca (Balearic Islands), 1820-70. En: Chircop, J. y Martínez, F. J. (eds.). Mediterranean quarantines, 1750-1914. Space, identity and power. Manchester University Press, Manchester, pp. 280-299.
Rangel de Almeida, J. J., 2012. 1851 International Sanitary Conference and the construction of an international sphere of public health. University of Edinburgh, Edinburgh.

Salas Vives, P., 2010a. Libertad y/o derecho a la vida. El resguardo sanitario durante el primer liberalismo (Mallorca, siglo XIX). Historia Social, 68, 69-85.

Salas Vives, P., 2010b. Port d'Alcúdia versus port de Pollença. VI Jornades d'estudis locals d'Alcúdia, pp. 137-148. Ajuntament d'Alcúdia, Alcúdia.

Salas Vives, P. y Pujadas Mora, J. M., 2016. El cólera como conflicto y factor de legitimación. Palma, 1865. Ayer, 101, 189-212.

Salas Vives, P. y Pujadas Mora, J. M., 2018. Cordons Sanitaires and the Rationalisation Process in Southern Europe (Nineteenth-Century Majorca). Medical History, 62, 314-332.

Serna, J., Pons, A., 2000. Cómo se escribe la Microhistoria. Frónesis, Cátedra, Universitat de València, València.

Serrallonga Urquidi, J., 1996. Epidemias e historia social. Apuntes sobre el cólera en España, 1833-1865. Historia Social, 24, 7-21.

Serrano Marín, V., 2017. El orden Biopolítico. El Viejo Topo, Barcelona.

Slack, P., 2012. Plague: A very short introduction. Oxford University Press, Oxford.

Soler Gayà, R., 2004. Crònica dels Ports Balears. Documenta Balear, Palma de Mallorca.

Terrades, I., 1987. El Cavaller de Vidrà. De l'ordre i el desordre conservador a la muntanya catalana. Publicacions de l'Abadia de Montserrat, Barcelona.

Tognotti, E., 2013. Lessons from the History of Quarantine, from Plague to Influenza A. Emerging Infectious Diseases 19, 254-259.

Tortella, G., 1994. El desarrollo de la España contemporánea. Historia económica de los siglos xIx y xx. Alianza, Madrid.

Troesken, W., 2015. The pox of Liberty: How the Constitution Left Americans Rich, Freee, and Prone to Infection. University of Chicago, Chicago.

Vidal Hernández, J. M., 2010. El viaje interrumpido: la vida en un lazareto marítimo, En: Perdiguero Gil, E. y Vidal Hernández, J. M. (eds.). La ciudadela de los fantasmas. Lazaretos y protección sanitaria en el mundo moderno. Institut Menorquí d'Estudis, Maó, pp. 103-128.

Weber, M., 1979. Economía y sociedad. Esbozo de sociología comprensiva. Fondo de Cultura Económica, México.

White, A. I. R., 2020. Historical linkages: epidemic threat, economic risk, and xenophobia. The Lancet, 395, 1250-1251. 